\title{
Genetic Testing in CYLD Cutaneous Syndrome: An Update
}

\author{
Nikoletta Nagy ${ }^{1,2}$ \\ Anna Dubois ${ }^{3}$ \\ Marta Szell ${ }^{1,2}$ \\ Neil Rajan (iD) 3,4 \\ 'Department of Medical Genetics, \\ University of Szeged, Szeged, Hungary; \\ ${ }^{2}$ Dermatological Research Group of the \\ Eotvos Lorand Research Network, \\ University of Szeged, Szeged, Hungary; \\ ${ }^{3}$ Department of Dermatology, Royal \\ Victoria Infirmary, Newcastle upon Tyne, \\ NEI 4LP, UK; ${ }^{4}$ Translational and Clinical \\ Research Institute, Newcastle University, \\ Newcastle upon Tyne, NEI 3BZ, UK
}

Correspondence: Neil Rajan Translational and Clinical Research Institute, Newcastle University, Newcastle upon Tyne, NEI 3BZ, UK Email neil.rajan@newcastle.ac.uk

\begin{abstract}
CYLD cutaneous syndrome (CCS) is an inclusive label for the inherited skin adnexal tumour syndromes Brooke-Spiegler Syndrome (BSS-OMIM 605041), familial cylindromatosis (FC - OMIM 132700) and multiple familial trichoepitheliomas (MFTOMIM 601606). All three syndromes arise due to germline pathogenic variants in CYLD, a tumour suppressor gene (OMIM 605018). CCS is transmitted in an autosomal dominant pattern, and has variable expressivity, both of the three syndromic phenotypes, and of the severity of tumour burden. Age-related penetrance figures are not precisely reported. The first tumours typically appear during puberty and progressively accumulate through adulthood. Penetrance is typically high, with equal numbers of males and females affected. Genetic testing is important for confirmation of the clinical diagnosis, genetic counselling and family planning, including preimplantation diagnosis. Additionally, identified CCS patients may be eligible for future clinical trials of non-surgical pre-emptive interventions that aim to prevent tumour growth. In this update, we review the clinical presentations of germline and mosaic CCS. An overview of the germline pathogenic variant spectrum of patients with CCS reveals more than 100 single nucleotide variants and small insertions and deletions in coding exons, most frequently resulting in predicted truncation. In addition, a minority of patients have large deletions involving the $C Y L D$ gene, intronic pathogenic variants that affect splicing, or inversions. We discuss germline and somatic testing approaches. Somatic testing of tumour tissue, relevant in mosaic CCS, can reveal recurrently detected pathogenic variants when two or more tumours are tested. This can influence genetic testing of children, who may inherit this as a germline variant, and inform genetic counselling and prenatal diagnosis. Finally, we discuss testing technologies that are currently used, their benefits and limitations, and future directions for genetic testing in CCS.
\end{abstract}

Keywords: CYLD gene testing

\section{Introduction}

CYLD cutaneous syndrome (CCS) is an inclusive label for the inherited skin adnexal tumour syndromes Brooke-Spiegler Syndrome (BSS-OMIM 605041), familial cylindromatosis (FC - OMIM 132700) and multiple familial trichoepitheliomas (MFT-OMIM 601606). All three syndromes arise due to germline pathogenic variants in CYLD. CCS patients develop multiple benign hair follicle tumours on the head and torso, ${ }^{1}$ which grow from puberty and accumulate throughout adulthood $^{2}$ (Figure 1A). ${ }^{3}$ The most frequent tumours seen in CCS are cylindromas, spiradenomas and trichoepitheliomas. The presentation of multiple cylindromas, and/or the related tumour spiradenoma, is exclusively seen in CCS, as is the presentation of multiple trichoepitheliomas in combination with cylindromas. In 
A

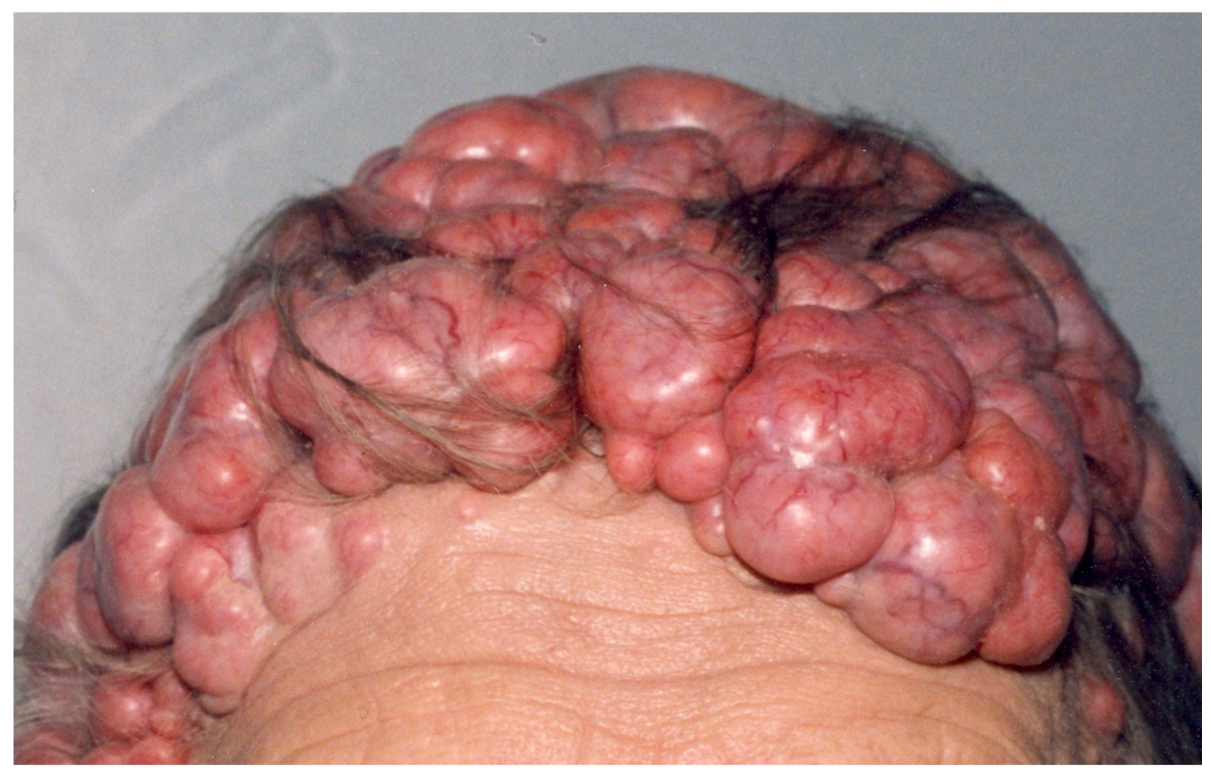

B
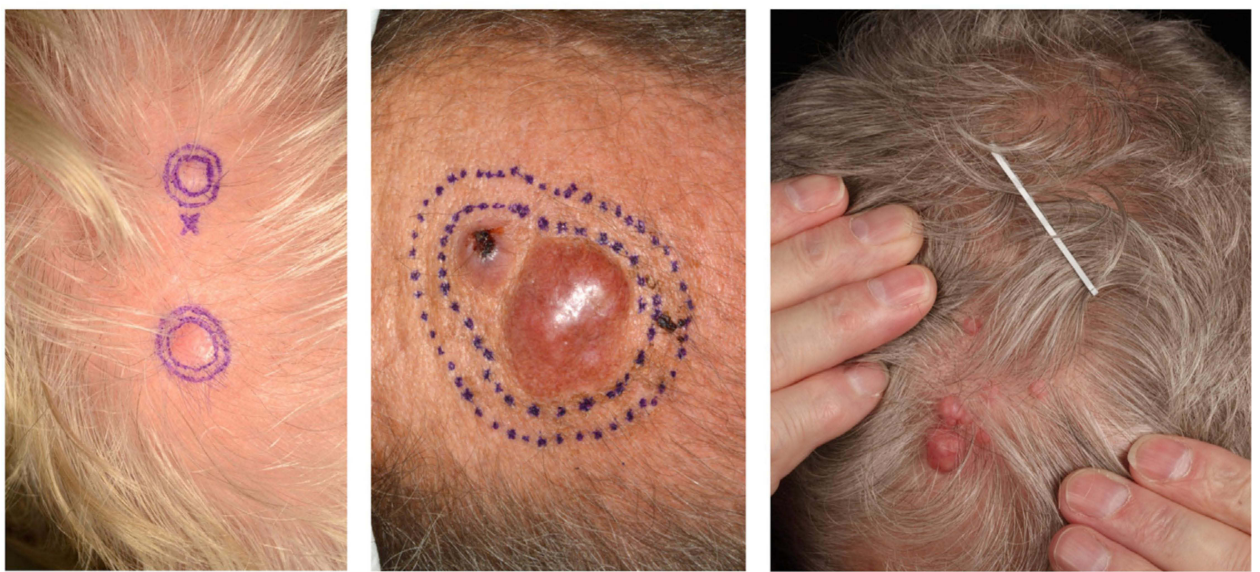

Figure I Cylindromas: germline and mosaic presentations. (A) Cylindromas and spiradenomas progressively grow and form a confluent mass, as seen in this severely affected patient with CCS. (B) Mosaic presentations of unilateral cylindromas, that may warrant skin biopsy and genetic testing to determine a recurrently detected pathogenic variant across multiple tumours. Image (B) reprinted from J Am Acad Dermatol, 8I, Arefi M, Wilson V, Muthiah S et al. Diverse presentations of cutaneous mosaicism occur in CYLD cutaneous syndrome and may result in parent-to-child transmission. 1300-1307, Copyright (2019), with permission from Elsevier. ${ }^{24}$

severe cases, tumours may cover most of the scalp or face, and sun-protected hair-bearing sites such as pubic skin can be affected. Despite an autosomal dominant pattern of inheritance, female CCS patients may be more severely affected, and whilst this has been reported in several families, the underlying mechanism for this disparity is not fully understood. ${ }^{4}$

$C Y L D$ is a tumour suppressor gene. Pathogenic variants in $C Y L D$ that give rise to CCS result in loss of function of the encoded protein. CCS patients are heterozygous for pathogenic variants in $C Y L D$ in all normal cells, ie, one copy of $C Y L D$ is mutated, but the remaining normal copy is functional. When the normal copy is mutated, the result is loss of functional CYLD, which can lead to the affected cell becoming neoplastic. It is believed that this "two-hit" mechanism ${ }^{5}$ occurs in hair follicle stem cells leading to the different skin adnexal tumours seen frequently in CCS. Recent genetic studies have confirmed that in cylindroma cells, both copies of $C Y L D$ are inactivated, and biallelic CYLD pathogenic variants alone appear sufficient to drive 
tumourigenesis. ${ }^{6}$ Malignant transformation of skin tumours has been described, where additional genetic changes in addition to biallelic CYLD mutations are reported. ${ }^{6}$

\section{Clinical Phenotype of CCS}

Cylindromas are smooth nodular tumours which are typically pink in colour, although can have a translucent appearance. Blood vessels may be seen across the surface of the tumour (Figure 2A). Cylindromas grow progressively over many years, and at presentation skin tumours may be several centimetres in size. ${ }^{7}$ Spiradenomas (Figure 2B) are also nodular and may have a striking blue/black colour; sometimes this is only noticed intraoperatively. Spiradenomas are usually reported to be

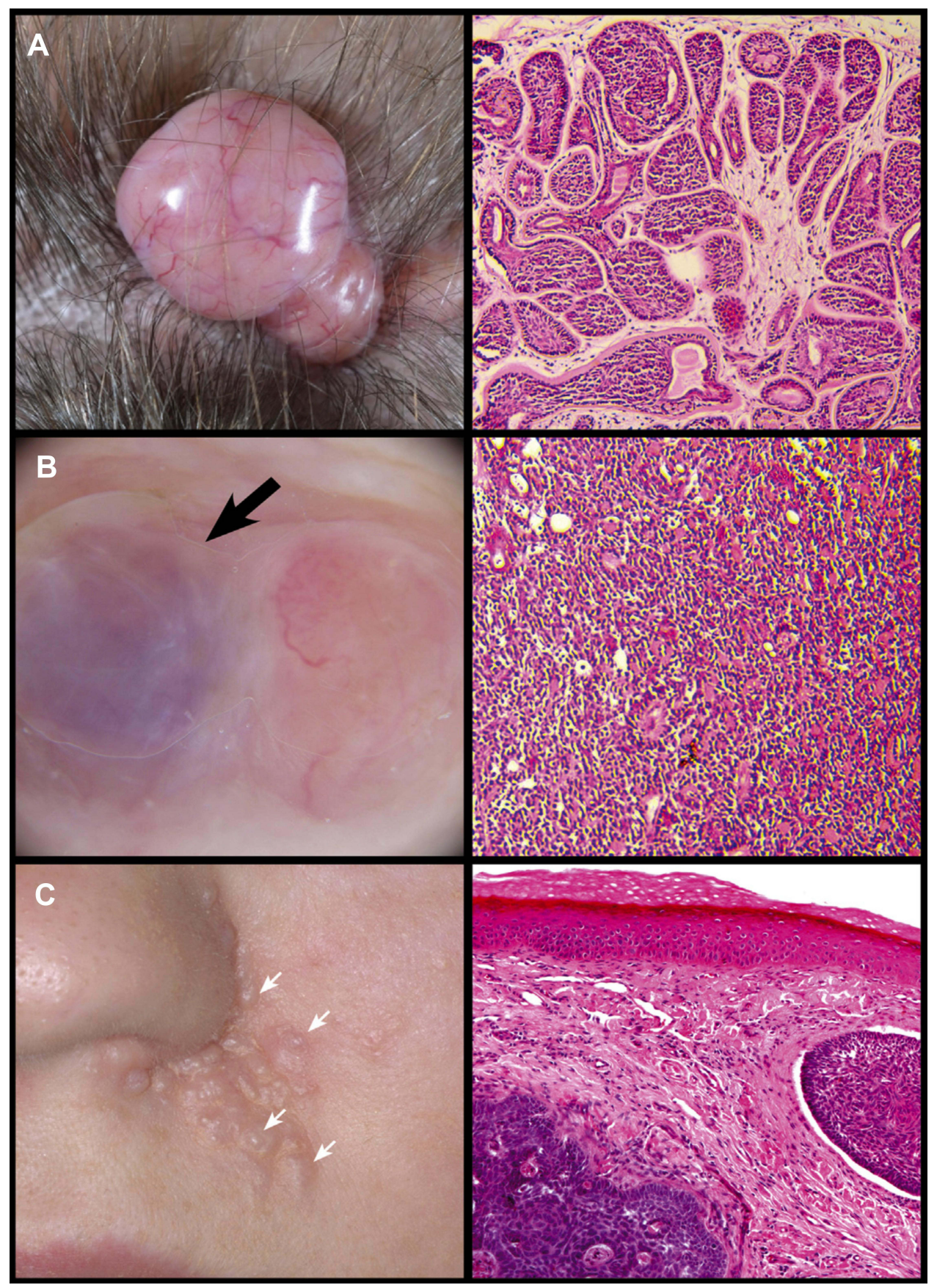

Figure 2 Skin tumours frequently seen in CCS. (A) Cylindroma. (B) Spiradenoma indicated by black arrow. (C) Trichoepithelioma indicated by white arrows. Reprinted from Dermatol Clin, 35 (I), Dubois A, Hodgson K, Rajan N. Understanding Inherited Cylindromas: Clinical Implications of Gene Discovery. 6I-7I, Copyright (20I7), with permission from Elsevier. ${ }^{116}$ 
painful and can grow quickly compared to cylindromas. Features of both lesions are also seen to occur in a single tumour, in keeping with the histological finding of cylindrospiradenoma discussed below. Trichoepitheliomas (Figure 2C) are skin-coloured, small, papular tumours, usually found on the perinasal, melo-labial and glabellar skin. In patients with European ancestry, they are usually 3-4mm across. In patients with African, Indian, and Chinese ancestry, trichoepitheliomas may be larger and the face may be the predominant tumour site, with few cases of confluent scalp tumours reported in the literature. Milia may also be seen in CCS patients and are sometimes the only indication of carrier status in a pedigree with $\mathrm{CCS}^{8}$

\section{Histologic and Genetic Features of CCS Skin Tumours}

CCS skin tumours are postulated to arise from hair follicle stem cells, due to clinical features such as presentation at hair-bearing sites and expression of histological markers seen in hair follicles (Figure 2A-C) ${ }^{9-11}$ Cylindromas are non-encapsulated nodular tumours that extend into the dermis. Basaloid tumour cells are usually arranged in a cylindrical pattern, apparent when the tumour is sectioned, which originally inspired the name cylindroma. Each "cylinder" is arranged in a jigsaw pattern, separated by a thickened basement membrane. ${ }^{12}$ Compared to cylindroma, tumour cells in spiradenomas are disorganised. A dense basophilic cellular proliferation is seen and typically lymphocytes are present. Skin tumours in CCS patients may demonstrate clinical and histological features consistent with both cylindroma and spiradenoma. Spiradenocylindroma is a term that has been coined to capture this frequent histophenotype. ${ }^{13,14}$ It is now recognised that cylindroma and spiradenoma represent different levels of organisation of the same tumour type. Epigenetic dysregulation of the Wnt signalling pathway has been shown to be associated with the development of spiradenoma. ${ }^{15}$ Recent studies of CCS tumours using whole-genome sequencing have shown that additional epigenetic modifier genes DNMT3A and BCOR are somatically mutated in these tumours, and may also explain the transition to spiradenoma. ${ }^{6}$ Notably, sporadic spiradenomas do not usually carry $C Y L D$ mutations, but instead have mutations in ALPK1. ${ }^{16}$ Trichoepitheliomas are comprised of basaloid cells, with palisading evident peripherally. Mesenchymal papillary bodies may also be seen.
Again, biallelic $C Y L D$ mutations have been described in these tumours recently. ${ }^{6}$

\section{The Clinical Burden of Disease in CCS}

The "benign" histological label applied to CCS frequently fails to capture the clinical burden of disease faced by CYLD pathogenic variant carriers. The progressive growth of these tumours is not widely documented in the existing literature, and small studies have shown that the majority of CCS tumours grow over time, making early surgery a useful intervention. The severity of the phenotype may be assessed by multiple factors including the total number of skin tumours, tumour size, tumour symptoms and the presence of malignant tumours. In some cases, the need for repeated surgery from an early age and complete scalp removal serve as proxy markers of tumour burden. The tumours and the surgical procedures themselves can be disfiguring in patients who are severely affected. Total scalp excision is considered a last resort to address severely affected cases, where tumours form a confluent mass affecting large areas of the scalp. ${ }^{17}$ It is thought that early pre-emptive surgery may reduce the need for, or delay, total scalp excision. CCS tumours favour the ear canal, and the patency and consequently hearing of CCS patients may be impaired. This is a challenging site for surgical intervention, and tumours are preferably removed before they cause deafness. ${ }^{18}$ Exceptionally, patients with severe periocular trichoepitheliomas may experience impairment of visual fields and eyelid opening. The pubic and perineal skin is another favoured site of CCS tumour development. Painful spiradenomas at this site may impair sexual function. Patients with CCS have been reported with depression and social withdrawal due to their skin tumour burden.

\section{Mosaic Presentations of CCS}

Patients may present with only a cluster of CCS tumours arranged in a linear, often unilateral pattern. ${ }^{19,20}$ These lines are recognised to correspond to the lines of Blaschko (Figure 1B), ${ }^{21}$ which are linear bands of skin that are thought to develop from a single epidermal progenitor cell during fetal development. ${ }^{22}$ Such presentations reflect genetic mosaicism, where some cells carry a different genetic sequence from the rest of the person. There are two genetic scenarios relating to mosaicism to consider in CCS. The first is in an individual whose parent 
has CCS and has transmitted a heterozygous pathogenic variant in CYLD in the germline of the fetus. A further random somatic mutation in the remaining normal allele of $C Y L D$ occurring during early fetal development will result in both copies of the CYLD gene being inactivated in that progenitor cell. Daughter cells from this progenitor cell contributing to the line of Blaschko will be predisposed to develop cutaneous tumours, sometimes from childhood. ${ }^{23}$ Alternatively, a somatic mutation in CYLD may occur at during early fetal development in an individual whose parent does not have CCS, and in such cases the daughter cells contributing to a line of Blaschko will still have one working copy of the CYLD gene. These patients typically develop tumours in a unilateral cluster later in adult life, when additional second hits affecting the $C Y L D$ gene in this band occur. Genetic analysis of two or more such skin tumours should demonstrate a recurrently detected CYLD pathogenic variant. These patients may also demonstrate a low level of the same pathogenic variant in blood leucocyte DNA, demonstrable with next-generation sequencing techniques sensitive to detect low-level mosaicism, if the post-zygotic mutational event occurred in a cell that contributed to both skin and blood lineages. ${ }^{24}$

\section{Malignancy in CCS}

Cutaneous malignancy is well recognised in CCS, although it occurs relatively infrequently. ${ }^{25}$ Cylindroma and spiradenoma may both undergo malignant transformation, or apparent de novo skin malignancies may arise in CCS patients. Clinical features that should be reported by patients as they are associated with cutaneous malignancy are as follows: tumour ulceration; rapid tumour growth; tumour pain; intermittent bleeding from a tumour, colour change in the surface of the tumour; tethering of the tumour to underlying bone. ${ }^{26}$ Invasion through the skull plate has been observed, ${ }^{27,28}$ supporting the use of radiological imaging in selected advanced CCS cases preoperatively. Malignant CCS tumours may metastasise to other tissues including the liver, lungs and bones. ${ }^{25}$ In patients with malignant metastatic disease, death from metastatic CCS disease has been reported in patients as young as 42 years of age. ${ }^{29}$

The histological features seen in malignant CCS tumours have been reported ${ }^{29}$ to include salivary gland type basal cell adenocarcinoma-like pattern, low-grade (BCAC-LG) and high-grade BCAC. Sarcomatoid (metaplastic) carcinoma and invasive adenocarcinoma are also recognised. Comprehensive genomic analyses, performed in just a small number of cases so far, have provided new insights, and suggest that molecular analysis of these tumours may aid classification. ${ }^{6}$ A case of poorly differentiated adenocarcinoma from the skin of a CCS patient that underwent whole-exome sequencing demonstrated somatic mutations in TP53 and EP300. In a case of BCAC-LG, a mutation in BCOR in addition to biallelic mutations in $C Y L D$ was found. Finally, a case of spiradenocarcinoma was found to have homozygous MBD4 mutations, and this tumour also had a mutation in the gene that encodes the epigenetic modifier KDM6A.

In addition to the adnexal carcinomas above, cutaneous squamous cell carcinoma (cSCC) arising in patients with CCS has been described in isolated reports ${ }^{30,31}$ as well as follicular cSCC. $^{32}$ Trichoblastic carcinoma has been reported to arise from preexisting trichoblastoma in $\mathrm{CCS},{ }^{33}$ which can metastasise. BCC has been reported to arise from trichoepithelioma, ${ }^{34}$ and has been reported to be associated with mutations in PTCH1 in addition to CYLD. In a recent study of a South American family with CCS, BCC was reported in $25 \%$ of affected patients. ${ }^{35}$

\section{Salivary Gland Tumours}

A benign salivary gland tumour termed membranous basal cell adenoma (MBCA) $)^{36}$ is recognised to develop infrequently in CCS, usually after the age of 40. Presentation of MBCA in the parotid gland may be unilateral or bilateral. MBCA can be managed surgically, but recurs in up to $25 \%$ of cases. ${ }^{37}$ MBCA may transform to adenocarcinoma in CCS, but this is rare. ${ }^{38,39}$

\section{Pulmonary Cylindromas}

Lung metastases resulting from cutaneous cylindromas are recognised (Figure 3). ${ }^{40-42}$ These pulmonary tumours may be single or multiple and have been considered to be "benign" metastases, as there is no history of a primary malignant cutaneous cylindroma in the skin, an absence of lymph node disease, and benign histology in pulmonary cylindromas. Pulmonary tumours may present with breathlessness, and at times warrant surgical interventions such as endoscopic laser ablation or surgery to maintain lung function, as they may be present for several years. The true rate of these tumours in CCS patients is not currently known, as some of these tumours are asymptomatic. Recently, whole-genome sequencing of pulmonary cylindromas demonstrated a pathogenic variant in $A K T 1$ in addition to biallelic mutations in $C Y L D$. Mutational signature and clonality analysis of multiple tumours 

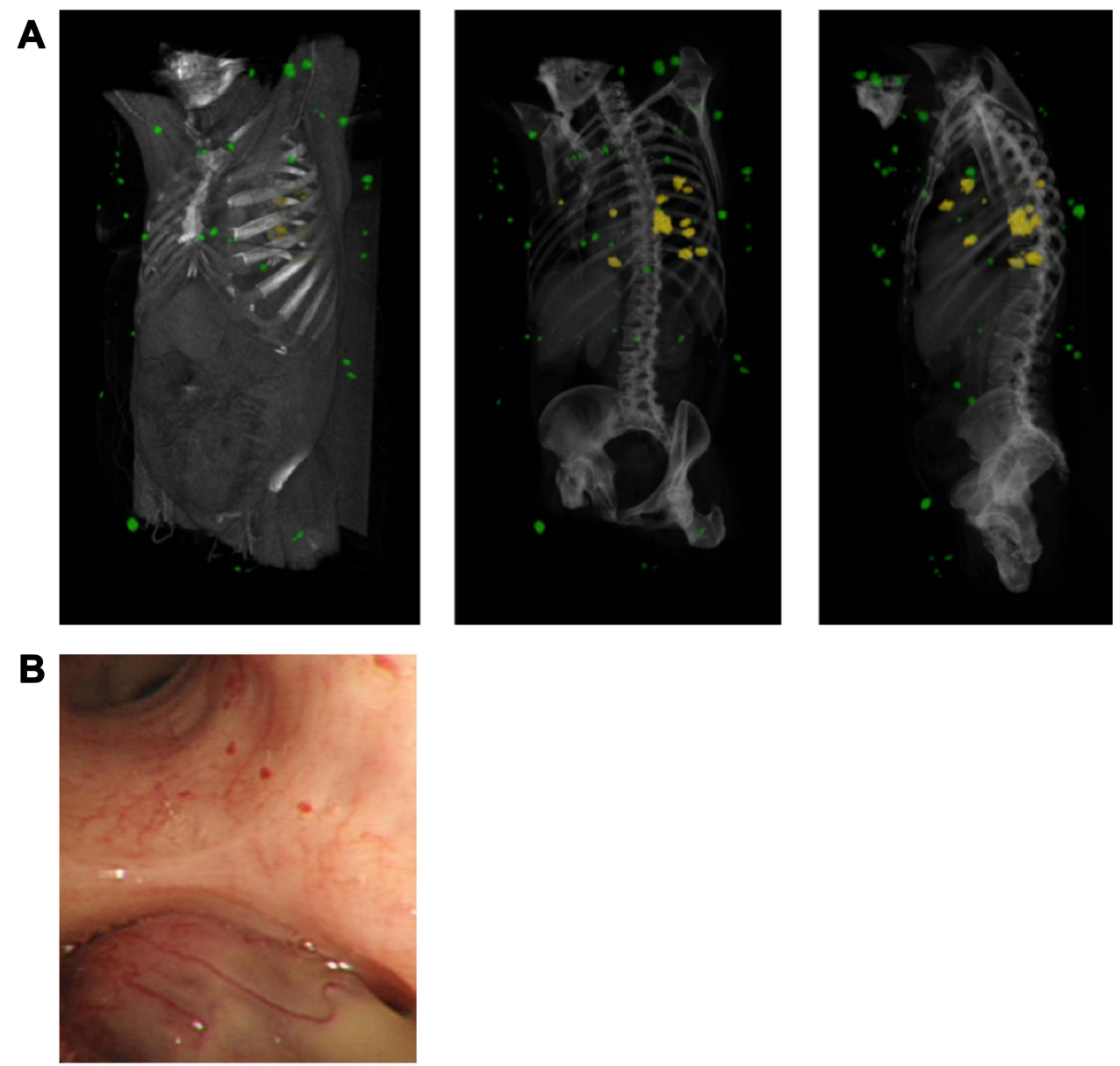

Figure 3 Pulmonary and cutaneous cylindromas visualised radiologically and endoscopically. (A) Spatial location of cutaneous CCS tumours seen on a CT with contrast indicated in green, and pulmonary CCS tumours indicated in yellow. Adapted from (B) Intra bronchial CCS tumour visualised during bronchoscopy. Adapted with permission from Brown SM, Arefi M, Stones R, et al. Inherited pulmonary cylindromas: extending the phenotype of CYLD mutation carriers. Br J Dermatol. 2018; I79:662-668. C 20I8 The Authors. British Journal of Dermatology published by John Wiley \& Sons Ltd on behalf of British Association of Dermatologists. ${ }^{41}$

demonstrated the presence of a UV mutation signature, confirming origin from a cutaneous skin tumour. ${ }^{6}$

\section{CYLD as a Causative Gene for CCS}

$C Y L D$ was discovered using DNA samples from carefully phenotyped pedigrees of families with FC, BSS and MFT. The CYLD locus was mapped to chromosome $16^{43}$ using linkage analysis of large CCS families from the North of England, and the CYLD gene was subsequently found to be mutated in patients with BSS, FC and MFT phenotypes. ${ }^{44-46}$ Linkage studies suggest that CCS is a single locus disease, ${ }^{45}$ and supports the encompassing term CCS. A minority of cases deemed "mutationnegative" by Sanger sequencing have been subsequently shown to have large rearrangements that disrupt $C Y L D,{ }^{47}$ intronic variants that impact on $C Y L D$ splicing ${ }^{48}$ or large contiguous deletions that include $C Y L D$ and adjacent genes. ${ }^{49}$ Of note, whilst CYLD mutations in CCS cause loss of function, gain of function mutations in $C Y L D$ have recently been reported in familial frontotemporal dementia - amyotrophic lateral sclerosis, ${ }^{50}$ extending the roles of the $C Y L D$ gene in human disease.

CYLD spans a $56 \mathrm{~kb}$ genomic footprint and has 20 exons (Figure 4A) ${ }^{51}$ It encodes an ubiquitin hydrolase enzyme that is involved in removing ubiquitin molecules that are "tagged" on a range of protein substrates as post-translational modifications, influencing the function, localisation and docking of ubiquitin-tagged proteins. CYLD demonstrates specificity for protein substrates tagged with lysine 63 linked and Met 1 ubiquitin chains. ${ }^{52,53}$ CYLD function has been extensively reviewed. ${ }^{54-57}$ Importantly in the context of CCS, CYLD negatively regulates several key cell survival pathways important in hair development, growth and maintenance, including NF- $\kappa \mathrm{B},{ }^{58} \mathrm{Wnt}^{59}{ }^{50 t c h}{ }^{60}$ and TGF- $\beta,{ }^{61}$ which are also 
A

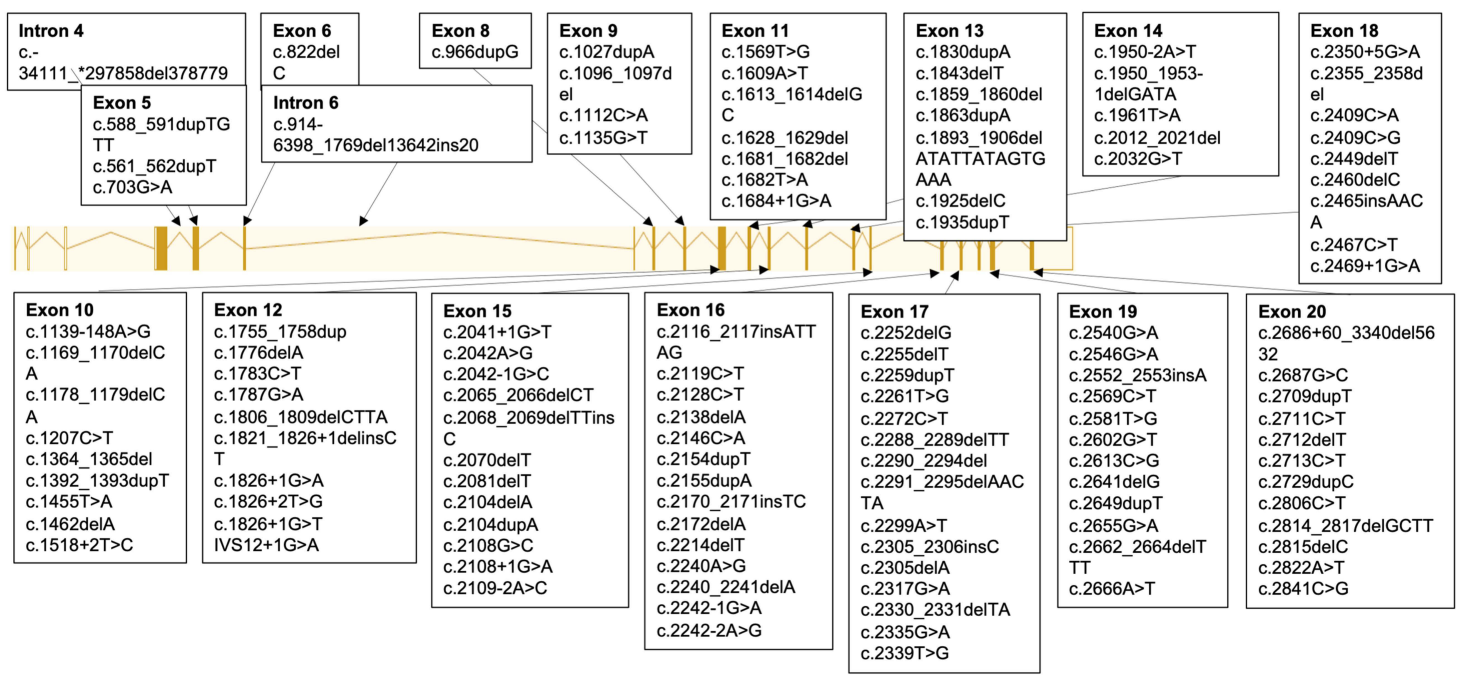

B

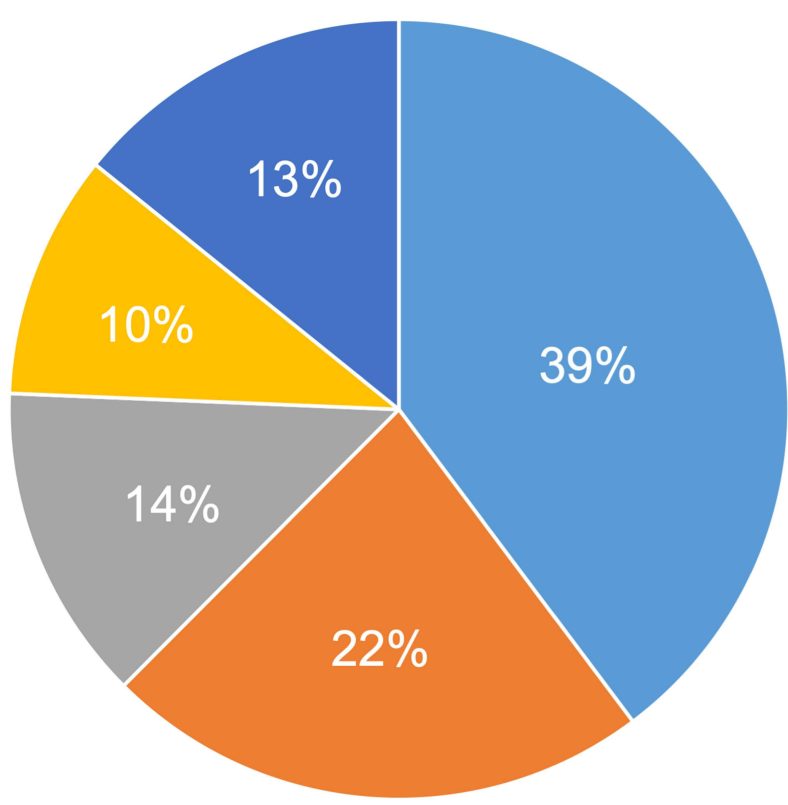

Frameshift mutations Nonsense mutations Splice site mutations Missense mutations Others

Figure 4 CYLD gene pathogenic variants identified to date. (A) Exonic locations of CYLD pathogenic variants in CCS patients; note a predisposition to the 3' end of the gene, from which the catalytic domains are encoded. (B) Frameshift and nonsense pathogenic variants resulting in a predicted truncating protein are the most frequent mutation type seen.

important in inflammation and cancer. Deregulation of NF-KB and Wnt signalling pathways following loss of functional CYLD in CCS tumour cells has been demonstrated, and may play a central role in tumorigenesis. ${ }^{6,62}$

\section{Germline Pathogenic Variants in CCS}

The first 21 pathogenic variants in CYLD were identified in $2000{ }^{44}$ Fifteen years later the number had risen to $95,{ }^{63}$ increasing further to 107 in the last six years. ${ }^{64-69}$ Pathogenic variants are named according to Human Genome Variation Society (HGVS) nomenclature guidelines (www.HGVS.org). These are numbered with respect to the CYLD gene reference sequence (ENSG00000083799 corresponding to the CYLD gene and ENST00000311559 corresponding to the CYLD transcript). Here, we review previously published $C Y L D$ pathogenic variants (Table 1) and also report two which are novel: a heterozygous four-base deletion 
Table I List of Published Pathogenic Variants in CCS

\begin{tabular}{|c|c|c|c|c|}
\hline Paper & Year & Mutation & Exon & Mutation Type \\
\hline Vanecek et al. & 2014 & c.-34III_*297858del378779 & N/A & Large deletion \\
\hline Nasti et al. & 2009 & c.56I_562dupT & 5 & NS \\
\hline Parren et al. & 2018 & c.588_59IdupTGTT & 5 & FS \\
\hline Shiver et al. & 2015 & c. $703 \mathrm{G}>\mathrm{A}$ & 5 & MS \\
\hline Parren et al. & 2018 & c.822delC & 6 & FS \\
\hline Vanecek et al. & 2014 & c.914-6398_I769del|3642ins20 & N/A & Large deletion \\
\hline Dubois et al. & 2015 & c.966dupG & 8 & FS \\
\hline Grossman et al. & 2013 & c. 1027dupA & 9 & FS \\
\hline Saggar et al. & 2008 & c.1096_1097del & 9 & FS \\
\hline Bignall et al, Bowen et al, Saggar et al. & $2000 ; 2005 ; 2008$ & c. $1112 C>A$ & 9 & NS \\
\hline Almeida et al. & 2008 & c. $1135 G>T$ & 9 & NS \\
\hline Kazakov et al. & 2009 & c. $1139-\mid 48 A>G$ & 10 & Splice \\
\hline Wu et al. & 2014 & c.1169_II70delCA & 10 & FS \\
\hline Ying et al. & 2012 & c.1178_II79delCA & 10 & FS \\
\hline Almeida et al. & 2008 & c. $1207 \mathrm{C}>\mathrm{T}$ & 10 & NS \\
\hline Liang et al. & 2008 & c.1364_1365del & 10 & FS \\
\hline Nasti et al. & 2009 & c.1392_1393dupT & 10 & NS \\
\hline Bignell et al. & 2000 & c. $1455 \mathrm{~T}>\mathrm{A}$ & 10 & NS \\
\hline Zheng et al. & 2004 & c. I 462delA & 10 & FS \\
\hline Ly et al. & 2004 & c. $1518+2 T>C$ & 10 & Splice \\
\hline Bignell et al. & 2000 & c. $1569 \mathrm{~T}>\mathrm{G}$ & 11 & NS \\
\hline Solak et al. & 2019 & c. $1609 \mathrm{~A}>\mathrm{T}$ & II & NS \\
\hline Andersson et al. & 2019 & c.1613_I614delGC & II & FS \\
\hline Saggar et al. & 2008 & c. $1628 \_1629 \mathrm{del}$ & 11 & NS \\
\hline Bignell et al. & 2000 & c. $168 \mathrm{I} \_1682 \mathrm{del}$ & 11 & FS \\
\hline van den Ouweland et al. & 2011 & c. $1682 T>A$ & 11 & NS \\
\hline Kazakov et al. & 2010 & c. $|684+| G>A$ & II & Splice \\
\hline Bowen et al; Saggar et al. & 2005,2008 & c.1755_1758dup & 12 & FS \\
\hline Bignell et al. & 2000 & c. I776delA & 12 & FS \\
\hline Pinho et al. & 2015 & c. $1783 \mathrm{C}>\mathrm{T}$ & 12 & NS \\
\hline Zuo et al. & 2007 & c. $1787 \mathrm{G}>\mathrm{A}$ & 12 & MS \\
\hline Nagy et al. & 2021 & c.1806_1809delCTTA & 12 & NS \\
\hline Tantcheva-Poór et al. & 2016 & c. $182\left|\_\right| 826+\mid$ delinsCT & 12 & FS \\
\hline Huang et al. & 2009 & c. $1826+\mid G>A$ & 12 & Splice \\
\hline Liang et al. & 2005 & c. $1826+2 T>G$ & 12 & Splice \\
\hline Kazakov et al. & 2011 & c. $1826+\mid G>T$ & 12 & Splice \\
\hline Huang et al. & 2009 & $|V S| 2+\mid G>A$ & 12 & Splice \\
\hline Bignell et al, Saggar et al. & 2000,2008 & c. 1830 dupA & 13 & FS \\
\hline Reuven et al. & 2013 & c. 1843delT & 13 & FS \\
\hline Bignell et al, Saggar et al. & 2000,2008 & c.1859_I860del & 13 & FS \\
\hline Saggar et al. & 2008 & c.1863dupA & 13 & FS \\
\hline Nasti et al. & 2009 & c.1893_1906delATATTATAGTGAAA & 13 & NS \\
\hline Chen et al. & 2011 & c. 1925delC & 13 & FS \\
\hline Bignell et al. & 2000 & c. 1935dupT & 13 & NS \\
\hline Nasti et al. & 2009 & c. $1950-2 A>T$ & 14 & Splice \\
\hline Nasti et al. & 2009 & c.1950_1953-IdelGATA & 14 & Splice \\
\hline Kazakov et al. & 2009 & c. $1961 \mathrm{~T}>\mathrm{A}$ & 14 & MS \\
\hline Heinritz et al. & 2006 & c.2012_202I del & 14 & FS \\
\hline Nagy $\mathrm{N}$ et al. & 2015 & c. $2032 \mathrm{G}>\mathrm{T}$ & 14 & NS \\
\hline Kacerovska et al. & 2013 & c. $204|+| G>T$ & 15 & Splice \\
\hline Almeida et al. & 2008 & c. $2042 A>G$ & 15 & MS \\
\hline
\end{tabular}

(Continued) 
Table I (Continued).

\begin{tabular}{|c|c|c|c|c|}
\hline Paper & Year & Mutation & Exon & Mutation Type \\
\hline Malzone et al. & 2015 & c. $2042-I G>C$ & 15 & Splice \\
\hline van den Ouweland et al. & 2011 & c.2065_2066delCT & 15 & FS \\
\hline van den Ouweland et al. & 2011 & c.2068_2069delTTinsC & 15 & FS \\
\hline Guardoli et al. & 2014 & c.2070delT & 15 & FS \\
\hline Almeida et al, Parren et al. & 2008,2018 & c. 208 I delT & 15 & NS \\
\hline Sima et al, Cakmak Genc et al. & 2010,2019 & c.2104delA & 15 & FS \\
\hline Salhi et al. & 2004 & c.2104dupA & 15 & FS \\
\hline Sima et al. & 2010 & c. $2108+1 G>C$ & 15 & Splice \\
\hline Parren et al. & 2018 & c. $2108+\mid G>A$ & 15 & Splice \\
\hline Parren et al. & 2018 & c. $2109-2 A>C$ & 15 & Splice \\
\hline Melly et al. & 2012 & c.2116_2117insATTAG & 16 & FS \\
\hline Sima et al. & 2010 & c. $2119 \mathrm{C}>\mathrm{T}$ & 16 & NS \\
\hline Zheng et al, Chen et al. & 2004,2011 & c. $2128 \mathrm{C}>\mathrm{T}$ & 16 & NS \\
\hline Bignall et al. & 2000 & c.2138delA & 16 & FS \\
\hline van den Ouweland et al. & 2011 & c. $2146 \mathrm{C}>\mathrm{A}$ & 16 & MS \\
\hline Saggar et al. & 2008 & c.2154dupT & 16 & FS \\
\hline Grossman et al. & 2013 & c.2155dupA & 16 & FS \\
\hline Sima et al. & 2010 & c.2170_217IInsTC & 16 & FS \\
\hline Bignall et al, Scheinfeld et al, Saggar et al. & $2000,2003,2008$ & c.2172delA & 16 & FS \\
\hline Saggar et al. & 2008 & c.22I4delT & 16 & FS \\
\hline Hu et al, Saggar et al. & 2003, 2008 & c. $2240 A>G$ & 16 & MS \\
\hline Liang et al. & 2005 & c.2240_224I delA & 16 & FS \\
\hline Fujii et al. & 2017 & c. $2242-I G>A$ & 16 & Splice \\
\hline Parren et al. & 2018 & c. $2242-2 A>G$ & 16 & Splice \\
\hline Poblete Gutierrez et al. & 2002 & c.2252delG & 17 & FS \\
\hline Hongli et al. & 2014 & c. 2255 delT & 17 & FS \\
\hline Kazakov et al. & 2011 & c.2259dupT & 17 & FS \\
\hline Parren et al. & 2018 & c. $226 I T>G$ & 17 & MS \\
\hline $\begin{array}{l}\text { Bignall et al, Oiso et al, Zhang et al, Farkas } \\
\text { et al. }\end{array}$ & $\begin{array}{l}2000,2004,2006 \\
2016\end{array}$ & $c .2272 \mathrm{C}>\mathrm{T}$ & 17 & NS \\
\hline Grossman et al. & 2013 & c.2288_2289delTT & 17 & FS \\
\hline Saggar et al. & 2008 & c.2290_2294del & 17 & FS \\
\hline Grossman et al. & 2013 & c.229I_2295delAACTA & 17 & FS \\
\hline Sima et al. & 2010 & c. $2299 \mathrm{~A}>\mathrm{T}$ & 17 & NS \\
\hline Bignell et al. & 2000 & c.2305_2306insC & 17 & FS \\
\hline Bowen et al; Saggar et al. & 2005,2008 & c. 2305 delA & 17 & FS \\
\hline Wang et al. & 2010 & c. $2317 \mathrm{G}>\mathrm{A}$ & 17 & MS \\
\hline Hester et al. & 2013 & c. $2330 \_233$ I delTA & 17 & FS \\
\hline Wang et al. & 2010 & c. $2335 \mathrm{G}>\mathrm{A}$ & 17 & MS \\
\hline Bowen et al, Saggar et al. & 2005,2008 & c. $2339 \mathrm{~T}>\mathrm{G}$ & 17 & NS \\
\hline Bignall et al. & 2000 & c. $2350+5 G>A$ & 18 & Splice \\
\hline Zhang et al. & 2004 & c.2355_2358del & 18 & FS \\
\hline Parren et al. & 2018 & c. $2409 \mathrm{C}>\mathrm{A}$ & 18 & NS \\
\hline Liang et al. & 2008 & c. $2409 C>G$ & 18 & NS \\
\hline Amaro $C$ et al. & 2010 & c.2449delT & 18 & NS \\
\hline Bignall et al. & 2000 & c. $2460 \mathrm{delC}$ & 18 & NS \\
\hline Hunstig et al. & 2015 & c. 2465 insAACA & 18 & FS \\
\hline Bignall et al. & 2000 & c. $2467 C>T$ & 18 & NS \\
\hline Bignall et al. & 2000 & c. $2469+$ IG>A & 18 & Splice \\
\hline Parren et al. & 2018 & c. $2540 \mathrm{G}>\mathrm{A}$ & 19 & NS \\
\hline Almeida et al. & 2008 & c. $2546 \mathrm{G}>\mathrm{A}$ & 19 & NS \\
\hline
\end{tabular}

(Continued) 
Table I (Continued).

\begin{tabular}{|c|c|c|c|c|}
\hline Paper & Year & Mutation & Exon & Mutation Type \\
\hline Scholz et al. & 2010 & c.2552_2553insA & 19 & FS \\
\hline Bignall et al. & 2000 & c. $2569 \mathrm{C}>\mathrm{T}$ & 19 & NS \\
\hline Parren & 2018 & c. 258 I T >G & 19 & MS \\
\hline Bignall et al, Oranje et al. & 2000,2008 & c. $2602 \mathrm{G}>\mathrm{T}$ & 19 & NS \\
\hline Nagy et al. & 2012 & c. $2613 C>G$ & 19 & MS \\
\hline Grossman et al. & 2013 & c.264IdelG & 19 & FS \\
\hline Parren et al. & 2018 & c.2649dupT & 19 & FS \\
\hline van den Ouweland et al. & 2011 & c. $2655 \mathrm{G}>\mathrm{A}$ & 19 & NS \\
\hline van den Ouweland et al. & 2011 & c.2662_2664delTTT & 19 & Deletion \\
\hline Tantcheva-Poór et al. & 2016 & c. $2666 \mathrm{~A}>\mathrm{T}$ & 19 & MS \\
\hline van den Ouweland et al. & 2011 & c. $2686+60 \_3340$ del5632 & 20 & Large deletion \\
\hline Espana et al. & 2007 & c. $2687 G>C$ & 20 & MS \\
\hline Furuichi et al. & 2012 & c.2709dupT & 20 & FS \\
\hline Ly et al. & 2008 & c. $27 \mid I C>T$ & 20 & MS \\
\hline Tantcheva-Poór et al. & 2016 & c. $27 \mid 2 \mathrm{delT}$ & 20 & FS \\
\hline Grossman et al. & 2013 & c. $2713 \mathrm{C}>\mathrm{T}$ & 20 & NS \\
\hline Sima et al. & 2010 & c.2729dupC & 20 & FS \\
\hline Bignall et al, Bowen et al, Young et al, & $2000,2005,2006$ & c. $2806 \mathrm{C}>\mathrm{T}$ & 20 & NS \\
\hline Saggar et al, Kazakov et al, Nagy et al. & $2008,2009,2013$ & & & \\
\hline Sima et al. & 2010 & c.28I4_28I7delGCTT & 20 & FS \\
\hline Qian et al. & 2014 & c.28I5delC & 20 & FS \\
\hline Zheng et al. & 2004 & c. $2822 \mathrm{~A}>\mathrm{T}$ & 20 & MS \\
\hline Nagy et al. & 2021 & c. $284 I C>G$ & 20 & NS \\
\hline
\end{tabular}

Note: All mutations described in relation to reference sequence NM_0I5247.

Abbreviations: FS, frameshift; NS, nonsense; MS, missense.

(c.1806_1809delCTTA) located in exon 12 detected in a Hungarian patient affected by CCS, and a nonsense pathogenic variant (c.2841C > G) in exon 20 identified in a CCS patient from the UK (Figure 4A). For the two novel reported mutations, written informed consents were obtained from the enrolled patients according to a protocol (Ref ID: BSSGENET-001, BSS-GENET-002) approved by the Local Ethics Committee and the National Public Health and Medical Officer Service in adherence to the Helsinki guidelines.

Across the 107 published pathogenic variants of the CYLD gene, almost all (99\%) identified pathogenic variants are located between exon 9 and 20, most frequently in exon 16, 17 or 20. The encoded CYLD protein has two known functional domains: three cytoskeleton-associated glycinerich domains (CAP-GLY) connecting CYLD to the microtubules and the ubiquitin-specific protease domain (USP) responsible for the deubiquitinase activity of the protein. ${ }^{70}$ The USP domain is coded by exons $12-20$, the region in which exists the majority $(80 \%)$ of identified CYLD pathogenic variants in CCS patients (Figure 4). ${ }^{63-69}$
Regarding mutation types (Figure 4B), the most common are frameshift mutations (39\%), which are responsible for approximately half of the reported CYLD diseasecausing variants. ${ }^{20,34,44,46-48,64-66,71-87}$ Nonsense mutations $(22 \%)$ account for one quarter of the total identified mutations. ${ }^{44,47,68,69,71,73,74,76,83,85,88-94}$ Missense mutations are represented with a relatively low number, just $10 \%$ of the CYLD pathogenic variants, ${ }^{47,48,67,71,74,85,88,95-99}$ and splice site mutations $14 \%{ }^{44,66,69,82,83,97,100-104}$ A small proportion of reported pathogenic variants are due to large deletions ${ }^{24,49}$ and rearrangements. ${ }^{47}$ It is of interest to note that more than 10 large deletions including CYLD and adjacent genes have been described in children in an online database of developmental disorders, DECIPHER. ${ }^{105}$ Renal hypoplasia and intellectual disability have been reported in these cases, and only a single case currently reports a skin tumour, but no histological data is available for this case. In other cases with contiguous deletions involving $C Y L D$, external ear abnormalities (pinnae), anal atresia and hypospadias in males has also been reported. ${ }^{24}$ 
Eleven percent of the $C Y L D$ pathogenic variants are recurrent. ${ }^{44,71-74,89-93,106,107}$ Haplotype analyses suggest that some of these recurrent pathogenic variants such as c. $2806 \mathrm{C}>\mathrm{T}$ and c. $2272 \mathrm{C}>\mathrm{T}$, reported in geographically distant patients including Japanese, Chinese, Spanish, Dutch, Austrian, Canadian, Irish, Czech and Hungarian, are located in regions that are likely to be mutational hotspots in $C Y L D{ }^{44,48,73,74,90-93,106}$

Genotype-phenotype correlation has not been established, and mutations do not appear to predict severity. The phenotypes seen with each mutation type vary even within families, both in terms of phenotypic presentation and tumour number. ${ }^{93,106}$ Besides several other presumed yet unidentified genetic, environmental or lifestyle causes, the observed high phenotypic diversity in CCS patients may also be explained by the presence of genetic variants located outside the $C Y L D$ gene locus that could modify the phenotype. ${ }^{108}$ Genetic variants identified in STAT3, TRAF3 and in NBR1 may alter the effect of the loss of CYLD function on NF-KB activity in CCS tumour cells. ${ }^{108}$ The results of recent functional analyses support the role of these genes in the modulation of CYLD function, ${ }^{109}$ and support larger scale investigations to discover phenotype modifier genes.

\section{Genetic Testing in CCS}

Before considering genetic testing for CCS, genetic disorders where multiple facial papules may be a presenting sign should also be considered. The differential diagnosis, in addition to the MFT phenotype of CCS for multiple facial papules, includes the following conditions: Birt-Hogg-Dubé syndrome: presents with multiple facial fibrofolliculomas and trichodiscomas due to germline pathogenic variants in $F L C N$. Tuberous sclerosis: presents with facial angiofibromas that may mimic trichoepitheliomas, and is due to pathogenic variants in TSC1 and TSC2. Neurofibromatosis, due to pathogenic variants in $N F 1$, has also been recognised as a mimic of CCS. ${ }^{110}$ Cowden syndrome may present with periauricular trichilemmomas, and is due to pathogenic variants in PTEN. Multiple facial trichoepitheliomas and severe hair loss should raise the possibility of Marie-Unna hypotrichosis, recently linked to a pathogenic variant in an untranslated inhibitory region in the open reading frame of $H R .{ }^{111}$ Multiple scalp tumours may represent trichilemmal cysts, and these are associated with pathogenic variants in PLCD1. These examples highlight the importance of dermatopathology assessment of these skin tumours. In some healthcare settings, these disorders are tested as a panel of genes, as discussed below.
Genetic testing to establish $C Y L D$ pathogenic variant status can be performed in patients satisfying clinical diagnostic criteria for CCS: 1) A patient with two or more cylindromas, spiradenomas or trichoepitheliomas (with at least one tumour being histologically confirmed); 2) A patient with a single (ideally histologically confirmed) cylindroma, spiradenoma or trichoepithelioma who has a family history of confirmed CCS (either based on genetic or histological information).

\section{Germline Testing for CCS}

The aim of germline DNA testing is to obtain sequence data covering the CYLD locus, typically of the coding exons where the majority of pathogenic variants lie (Figure 5). Peripheral blood leucocytes are the preferred DNA source but, in some cases, buccal swabs are used. It is helpful to check requirements with the receiving laboratory. Extracted DNA can be subject to a range of different assays, including PCR of the coding exons of $C Y L D$, targeted capture of CYLD followed by next-generation sequencing, either alone, as part of a panel of genes, or as part of a whole-exome capture, with analysis of selected genes (virtual panel). In England, for example, CYLD testing is currently available as part of panel genes used for the clinical presentation of "Multiple benign monogenic skin tumours" (https://panelapp.genomicsengland.co.uk/panels/558/).

Such sequence data from coding $C Y L D$ exons allow detection of single nucleotide missense, nonsense and splice site variants, as well as small indels that disrupt the reading frame. The study of RNA sequencing data derived from peripheral blood leucocytes can inform the reclassification of novel splice site variants of uncertain significance. The yield of such tests in patients with multiple scalp cylindromas ranges from $85 \%$ to $100 \%{ }^{74}$ In patients with the MFT phenotype alone, the yield may be lower, and in one study was $44 \%$. Overall, the rate from this study of all CCS phenotypes was $72 \% .{ }^{74}$ This aligns with our experience as a UK test centre receiving national referrals for CCS over a 5-year period, and detecting a pathogenic variant in $69 \%$ of the 56 pedigrees submitted. ${ }^{112}$ In mutation-negative cases, additional testing to determine copy number changes and large deletions may be achieved via MLPA or SNP arrays (Figure 5). In some settings, RNA sequencing data of mutationnegative cases can lead to the detection of deep intronic mutations. ${ }^{48}$ Increasingly, as whole-genome 


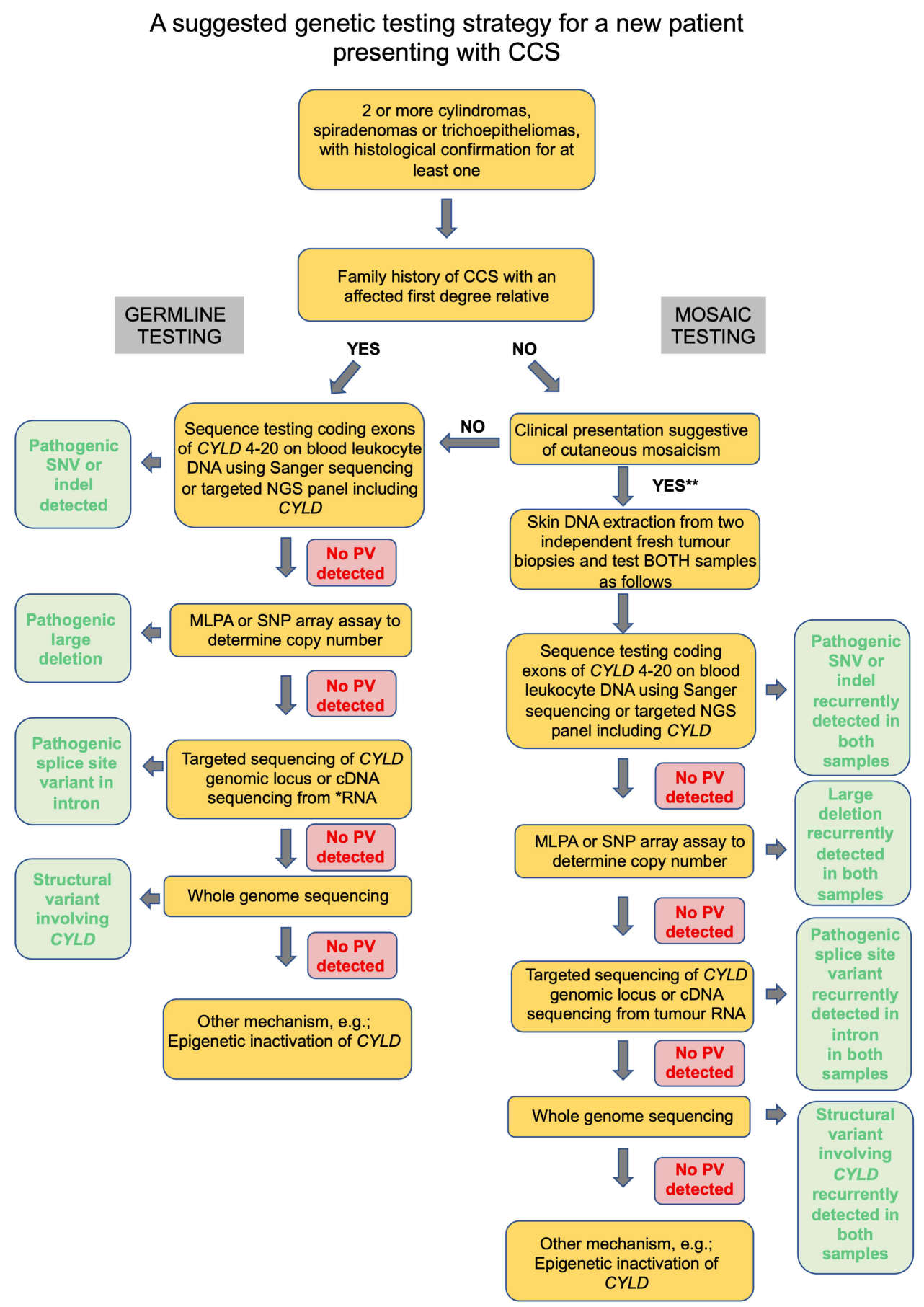

Figure 5 A suggested testing strategy for CCS that addresses germline and mosaic presentations. *RNA from blood leucocytes require special collection tubes; **in principle such a patient may still yet harbour a germline pathogenic variant, and it remains the clinician's decision if she would prefer to pursue GERMLINE testing first. Abbreviations: PV, pathogenic variant; SNV, single nucleotide variant.

sequencing reduces in cost, this may be a means to obtain comprehensive information on genetic variation involving $C Y L D$, including structural changes such as inversions or gene fusions. Providing $C Y L D$ coverage is of sufficient depth, there is the additional potential to detect mosaicism.

\section{Risk to Immediate Family in a Genotyped Individual with Germline CCS}

In most cases of germline CCS, the affected parent is clinically obvious. It can be helpful to determine the parental origin by 
confirmatory cascade testing where parental DNA is accessible and parents appear to be unaffected. CCS can present with subtle features, however, and some patients can be asymptomatic. If an unaffected parent of a proband is confirmed to have the proband's pathogenic variant, the proband's siblings have a $50 \%$ risk of also having inherited the familial pathogenic variant. In the scenario where neither parent is affected and does not carry the proband's pathogenic variant, this may represent a de novo pathogenic mutation. It is important to recognise that the risk to the proband's siblings in this case is still higher than the background population as either parent may have gonadal mosaicism. Cascade testing in the proband's siblings can determine their genetic status.

Children of the proband themselves also have a $50 \%$ risk of inheriting the familial pathogenic variant. Importantly, mutation analysis cannot currently prognosticate severity. Because intrafamilial clinical variability is observed in CCS, offspring who inherit a CYLD pathogenic variant may be more or less severely affected than the transmitting parent.

\section{Testing of Suspected Mosaic CCS Cases}

Unilateral clustered CCS skin tumours should lead the physician to consider a diagnosis of mosaic CCS. Suspected mosaic CCS patients can have two different genetic mechanisms for the presentation of unilateral CCS tumours as discussed above. Unilateral tumours and a family history of CCS should lead to germline testing of blood leucocyte DNA. ${ }^{113}$ In the absence of a family history, and a negative blood DNA result, CYLD sequencing of DNA from two CCS tumours from such a cluster should reveal a recurring pathogenic $C Y L D$ variant. This should ideally be done on fresh biopsies, as paraffin-embedded samples can be challenging to sequence due to DNA fragmentation. This approach may also benefit some cases with evidence of bilateral or multiple clusters where blood DNA testing is negative (Figure 6). Gonadal mosaicism in such cases is possible as discussed below. ${ }^{24}$

\section{Genetic Counselling Issues for Genotyped CCS Patients}

\section{Family Planning}

Genetic counselling can be informed by knowledge of genetic status, particularly in individuals that have not developed a clinical phenotype. Genetic testing is often discussed when a patient with CCS is considering family planning. A confirmed absence of the familial pathogenic variant in an at risk unaffected patient can assure the prevention of transmission of CCS to the next generation. The lack of ability to currently prognosticate severity in CCS based on genetic information makes a positive result less useful. In the context of prenatal testing, when a $C Y L D$ pathogenic variant is established in a family, prenatal testing and preimplantation genetic diagnosis (PGD) for pregnancies at increased risk are possible. A limitation of the ability to currently prognosticate severity and the variability of severity between generations should be discussed with the family when exploring such options.

Sporadic mosaic CCS cases may also have gonadal mosaicism, and there is a risk of parent-to-child transmission that is lower than in germline CCS. ${ }^{24}$ Knowledge of the mosaic pathogenic variant from skin tumour genetic assessment may allow techniques such DNA analysis of sperm in males to determine the level of gonadal mosaicism. Otherwise, PGD or other strategies may be considered in mosaic individuals who wish to use them when family planning.

\section{Surveillance of CCS Patients}

An annual full skin examination by a dermatologist is recommended in individuals with a clinical and/or genetic diagnosis of CCS. The frequency of follow-up can be tailored to the individual patient, as some patients require repeated surgery every three to four months if tumours continue to appear and grow. In patients with stable disease, or those without skin tumours, it may be reasonable to offer ad hoc follow-up. All CCS patients should be asked to report change in existing tumours such as rapid growth, tumours that appear different to existing lesions, or bleeding or ulcerated tumours. Dermatological assessment should be rapidly available for these patients, to determine if urgent excision is warranted. Clinical salivary gland examination may also be performed on an annual basis. Patients over 40 years of age reporting new-onset breathlessness should have pulmonary radiological imaging due to the potential risk of pulmonary cylindromas.

\section{Clinical Trials for Genotyped CCS Patients}

Treatment for CCS is predominantly surgical and is reviewed elsewhere. ${ }^{114}$ A placebo-controlled, phase $1 \mathrm{~b} / 2 \mathrm{a}$ clinical trial 

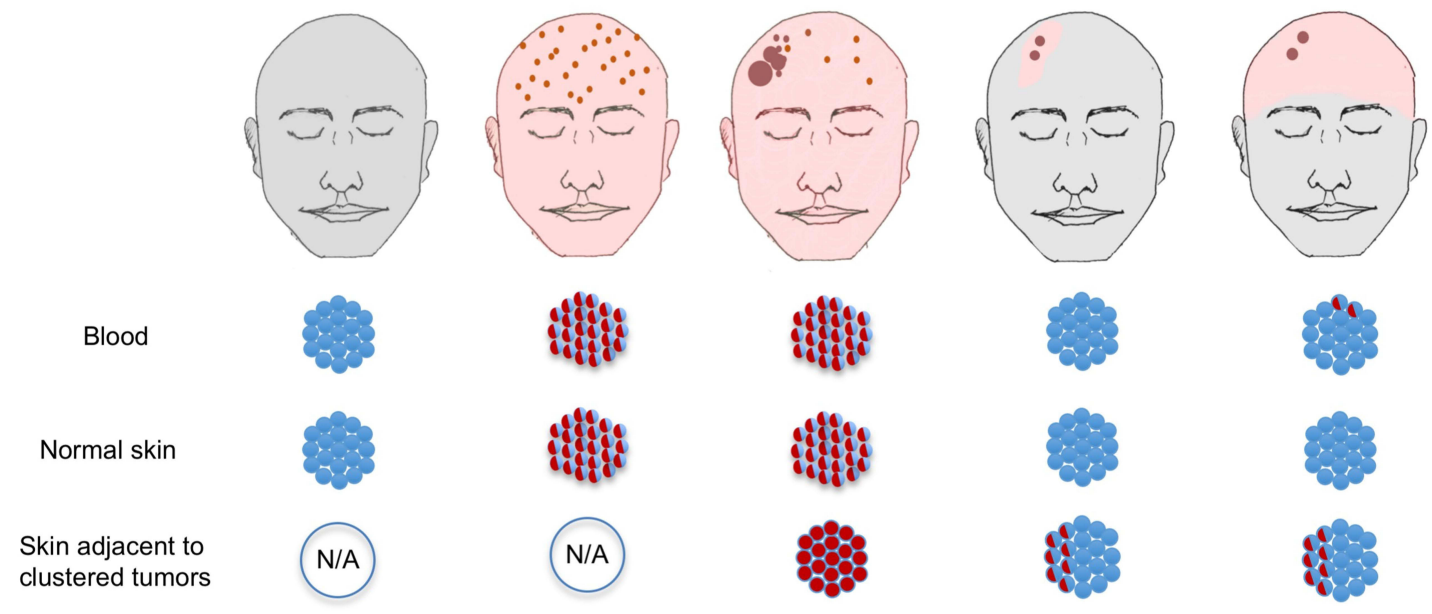

clustered tumors
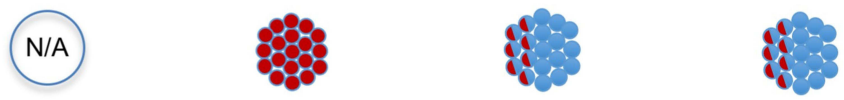

Tumors
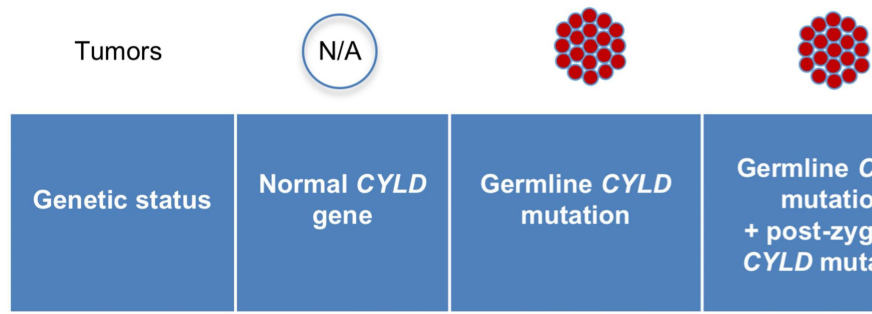

Germline CYLD

mutation

+ post-zygotic

CYLD mutation

Transmission

risk of CCS

to offspring

$0 \%$

$50 \%$

$50 \%$

Post-zygotic

CYLD mutation

detectable in

skin only*
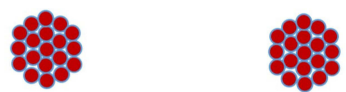

Post-zygotic

CYLD mutation

in multiple

tissues e.g. skin,

blood, gonads

Key: CCS tumor
Wildtype cell
- Heterozygous CYLD mutant cell
Biallelic CYLD mutant cell
N/A Not applicable

Figure 6 An overview of risk of transmission of germline and mosaic variants in CCS.

Notes: Reprinted from J Am Acad Dermatol, 8I, Arefi M, Wilson V, Muthiah S et al. Diverse presentations of cutaneous mosaicism occur in CYLD cutaneous syndrome and may result in parent-to-child transmission. 1300-1307, Copyright (2019), with permission from Elsevier. ${ }^{24}$

of a topical targeted kinase inhibitor (tropomyosin receptor kinase-Trk) has been reported and showed short-term safety. ${ }^{115}$ Additional research is needed to determine the utility of targeting Trk in CCS. There are isolated single-case reports of topical, intralesional or systemic interventions in CCS, but the generalisability of these are limited as they are not placebo controlled, they lack objective measures used to assess improvement and so far, only short-term follow-up is reported. Resources where new clinical trials are registered, and are regularly updated include www.clinicaltrials.gov and www. clinicaltrialsregister.eu.

\section{Concluding Statements}

Genetic testing in CCS has been advanced by nextgeneration sequencing technologies, in particular for mosaic presentations. Determining the pathogenic variant in $C Y L D$ in an affected patient with CCS influences genetic counselling and family planning decisions. Challenges ahead include 
the comprehensive delineation of disease modifying genes, such that clinicians are better placed to prognosticate regarding severity of future disease. In addition, the progressive molecular dissection of CCS skin tumours may yield targetable pathways that are amenable to pre-emptive therapeutic interventions in future clinical trials. Continued research in partnership with patients with CCS is essential to address these challenges.

\section{Acknowledgments}

NR's research is also supported by the Newcastle NIHR Biomedical Research Centre (BRC). The project received funding from the Hungarian Research Development and Innovation Office grants GINOP-2.3.2-15-2016-00039 and EFOP-3.6.1-16-2016-00008. We thank the patients for granting permission to publish this information. We are grateful to the patients for allowing the use of their clinical images.

\section{Disclosure}

The authors declare no conflicts of interest in this work.

\section{References}

1. Rajan N, Langtry JA, Ashworth A, et al. Tumor mapping in 2 large multigenerational families with CYLD mutations: implications for disease management and tumor induction. Arch Dermatol. 2009;145:1277-1284. doi:10.1001/ archdermatol.2009.262

2. Blake PW, Toro JR. Update of cylindromatosis gene (CYLD) mutations in Brooke-Spiegler syndrome: novel insights into the role of deubiquitination in cell signaling. Hum Mutat. 2009;30:1025-1036. doi:10.1002/humu.21024

3. Brown S, Worthy SA, Langtry JAA, et al. Tracking tumor kinetics in patients with germline CYLD mutations. $J$ Am Acad Dermatol. 2018;79:949-951. doi:10.1016/j.jaad.2018.04.014

4. van Balkom ID, Hennekam RC. Dermal eccrine cylindromatosis. J Med Genet. 1994;31:321-324. doi:10.1136/jmg.31.4.321

5. Knudson AG. Mutation and cancer: statistical study of retinoblastoma. Proc Natl Acad Sci US A. 1971;68:820-823. doi:10.1073/pnas.68.4.820

6. Davies HR, Hodgson K, Schwalbe E, et al. Epigenetic modifiers DNMT3A and BCOR are recurrently mutated in CYLD cutaneous syndrome. Nat Commun. 2019;10:4717. doi:10.1038/ s41467-019-12746-w

7. Evans CD. Turban tumour. Br J Dermatol. 1954;66:434-443. doi:10.1111/j.1365-2133.1954.tb12575.x

8. Bajwa DS, Nasr B, Carmichael AJ, et al. Milia: a useful clinical marker of CYLD mutation carrier status. Clin Exp Dermatol. 2018;43:193-195. doi:10.1111/ced.13296

9. Massoumi R, Podda M, Fassler R, et al. Cylindroma as tumor of hair follicle origin. J Invest Dermatol. 2006;126:1182-1184. doi:10.1038/sj.jid.5700218

10. Sellheyer K. Spiradenoma and cylindroma originate from the hair follicle bulge and not from the eccrine sweat gland: an immunohistochemical study with CD200 and other stem cell markers. J Cutan Pathol. 2015;42:90-101. doi:10.1111/cup.12406
11. Cotton DW, Braye SG. Dermal cylindromas originate from the eccrine sweat gland. $\mathrm{Br} J$ Dermatol. 1984;111:53-61. doi:10.1111/j.1365-2133.1984.tb04016.x

12. Bilroth T. Die cylindergeschwulst (cylindroma) in Untersuchungenuber die Entwicklung der Blutgefasse, nebstBeobachtungenaus der koniglichenchirugischenUniverstats-Klink zu Berlin. Berlin: Riemer Germany; 1856:1855-1869.

13. Michal M, Lamovec J, Mukensnabl P, et al. Spiradenocylindromas of the skin: tumors with morphological features of spiradenoma and cylindroma in the same lesion: report of 12 cases. Pathol Int. 1999;49:419-425. doi:10.1046/j.14401827.1999.00890.x

14. Kazakov DV, Magro G, Kutzner H, et al. Spiradenoma and spiradenocylindroma with an adenomatous or atypical adenomatous component: a clinicopathological study of 6 cases. $\mathrm{Am}$ $J$ Dermatopathol. 2008;30:436-441. doi:10.1097/DAD.0b0 $13 \mathrm{e} 3181812729$

15. Rajan N, Burn J, Langtry J, et al. Transition from cylindroma to spiradenoma in CYLD-defective tumours is associated with reduced DKK2 expression. J Pathol. 2011;224:309-321. doi:10.1002/path.2896

16. Rashid M, van der Horst M, Mentzel T, et al. ALPK1 hotspot mutation as a driver of human spiradenoma and spiradenocarcinoma. Nat Commun. 2019;10:2213. doi:10.1038/ s41467-019-09979-0

17. Freedman AM, Woods JE. Total scalp excision and auricular resurfacing for dermal cylindroma (turban tumor). Ann Plast Surg. 1989;22:50-57. doi:10.1097/00000637-198901000-00010

18. Langtry J, Rajan N. Pre-emptive intra-auricular electrosurgical resurfacing of cylindromas to prevent conductive deafness in CYLD cutaneous syndrome. Br J Dermatol. 2020;183:e188. doi:10.1111/bjd.19331

19. Chang YC, Colome-Grimmer M, Kelly E. Multiple trichoepitheliomas in the lines of Blaschko. Pediatr Dermatol. 2006;23:149-151. doi:10.1111/j.1525-1470.2006.00202.x

20. Furuichi M, Makino T, Yamakoshi T, et al. Blaschkoid distribution of cylindromas in a germline CYLD mutation carrier. $\mathrm{Br}$ $J$ Dermatol. 2012;166:1376-1378. doi:10.1111/j.1365-2133.20 12.10869.x

21. Blaschko A. Die Nevenverteilung in derhant in ihrer Beziehung zuden Ekrankungender Haut. In: Verhand Deust Dermatol Gessel. Breslan: VH Congress; 1901.

22. Moss C, Larkins S, Stacey M, et al. Epidermal mosaicism and Blaschko's lines. J Med Genet. 1993;30:752-755. doi:10.1136/ jmg.30.9.752

23. Happle R. Segmental forms of autosomal dominant skin disorders: different types of severity reflect different states of zygosity. Am J Med Genet. 1996;66:241-242. doi:10.1002/(SICI)10968628(19961211)66:2<241::AID-AJMG24>3.0.CO;2-S

24. Arefi M, Wilson V, Muthiah S, et al. Diverse presentations of cutaneous mosaicism occur in CYLD cutaneous syndrome and may result in parent-to-child transmission. J Am Acad Dermatol. 2019;81:1300-1307. doi:10.1016/j.jaad.2019.05.021

25. Gerretsen AL, van der Putte SC, Deenstra W, et al. Cutaneous cylindroma with malignant transformation. Cancer. 1993;72:1618-1623. doi:10.1002/1097-0142(19930901) 72:5<1618::AID-CNCR2820720521>3.0.CO;2-5

26. Durani BK, Kurzen H, Jaeckel A, et al. Malignant transformation of multiple dermal cylindromas. $\mathrm{Br} J$ Dermatol. 2001;145:653-656. doi:10.1046/j.1365-2133.2001.04460.x

27. Serracino HS, Kleinschmidt-Demasters BK. Skull invaders: when surgical pathology and neuropathology worlds collide. J Neuropathol Exp Neurol. 2013;72:600-613. doi:10.1097/ NEN.0b013e318299c40f 
28. Gildea JH, Lillehei KO, Golitz LE, et al. Benign cylindroma causing transcalvarial invasion in a patient with familial cylindromatosis. Clin Neuropathol. 2007;26:125-130. doi:10.5414/NPP26125

29. Kazakov DV, Zelger B, Rutten A, et al. Morphologic diversity of malignant neoplasms arising in preexisting spiradenoma, cylindroma, and spiradenocylindroma based on the study of 24 cases, sporadic or occurring in the setting of Brooke-Spiegler syndrome. Am J Surg Pathol. 2009;33:705-719. doi:10.1097/PAS.0b013 e3181966762

30. Ma H, Feng S, Pei W, et al. Twelve years' observation of multiple familial trichoepithelioma with squamous carcinoma. Indian J Dermatol. 2016;61:348. doi:10.4103/0019-5154.182464

31. Ganguly S, Jaykar KC, Banerjee PK, et al. Multiple familial trichoepitheliomas in association with squamous cell carcinoma. Indian Dermatol Online J. 2012;3:151-153. doi:10.4103/22295178.96726

32. Dubois A, Mestre T, Oliphant T, et al. Squamous cell carcinoma and multiple familial trichoepitheliomas: a recurrent association. Acta Derm Venereol. 2018;98:910-911. doi:10.2340/00015555-2988

33. Schulz T, Proske S, Hartschuh W, et al. High-grade trichoblastic carcinoma arising in trichoblastoma: a rare adnexal neoplasm often showing metastatic spread. Am $J$ Dermatopathol. 2005;27:9-16. doi:10.1097/01.dad.0000142240.93956.cb

34. Melly L, Lawton G, Rajan N. Basal cell carcinoma arising in association with trichoepithelioma in a case of Brooke-Spiegler syndrome with a novel genetic mutation in CYLD. J Cutan Pathol. 2012;39:977-978. doi:10.1111/j.1600-0560.2012.01952.x

35. Arruda AP, Cardoso-Dos-Santos AC, Mariath LM, et al. A large family with CYLD cutaneous syndrome: medical genetics at the community level. J Community Genet. 2020;11:279-284. doi:10.1007/s12687-019-00447-2

36. Jungehulsing $M$, Wagner $M$, Damm M. Turban tumour with involvement of the parotid gland. $J$ Laryngol Otol. 1999;113:779-783. doi:10.1017/S0022215100145190

37. Zarbo RJ. Salivary gland neoplasia: a review for the practicing pathologist. Mod Pathol. 2002;15:298-323. doi:10.1038/ modpathol.3880525

38. Hyman BA, Scheithauer BW, Weiland LH, et al. Membranous basal cell adenoma of the parotid gland. Malignant transformation in a patient with multiple dermal cylindromas. Arch Pathol Lab Med. 1988;112:209-211.

39. Kazakov DV. Brooke-Spiegler syndrome and phenotypic variants: an update. Head Neck Pathol. 2016;10:125-130. doi:10.1007/ s12105-016-0705-x

40. Vernon HJ, Olsen EA, Vollmer RT. Autosomal dominant multiple cylindromas associated with solitary lung cylindroma. $J$ Am Acad Dermatol. 1988;19:397-400. doi:10.1016/S0190-9622(88)70186-3

41. Brown SM, Arefi M, Stones R, et al. Inherited pulmonary cylindromas: extending the phenotype of CYLD mutation carriers. $\mathrm{Br}$ J Dermatol. 2018;179:662-668. doi:10.1111/bjd.16573

42. Bulau JE, Kreipe HH, Jessen E, et al. Pulmonary cylindromas in CYLD cutaneous syndrome: a rare differential diagnosis of pulmonary adenoid cystic carcinoma. Clin Lung Cancer. 2021. doi:10.1016/j.cllc.2021.03.016

43. Biggs PJ, Wooster R, Ford D, et al. Familial cylindromatosis (turban tumour syndrome) gene localised to chromosome 16q12-q13: evidence for its role as a tumour suppressor gene. Nat Genet. 1995;11:441-443. doi:10.1038/ng1295-441

44. Bignell GR, Warren W, Seal S, et al. Identification of the familial cylindromatosis tumour-suppressor gene. Nat Genet. 2000;25:160-165. doi:10.1038/76006

45. Takahashi M, Rapley E, Biggs PJ, et al. Linkage and LOH studies in 19 cylindromatosis families show no evidence of genetic heterogeneity and refine the CYLD locus on chromosome 16q12-q13. Hum Genet. 2000;106:58-65. doi:10.1007/s004399900227
46. Zhang XJ, Liang YH, He PP, et al. Identification of the cylindromatosis tumor-suppressor gene responsible for multiple familial trichoepithelioma. $J$ Invest Dermatol. 2004;122:658-664. doi:10.1111/j.0022-202X.2004.22321.x

47. van den Ouweland AM, Elfferich P, Lamping R, et al. Identification of a large rearrangement in CYLD as a cause of familial cylindromatosis. Fam Cancer. 2011;10:127-132. doi:10.1007/s10689-010-9393-y

48. Kazakov DV, Thoma-Uszynski S, Vanecek T, et al. A case of Brooke-Spiegler syndrome with a novel germline deep intronic mutation in the CYLD gene leading to intronic exonization, diverse somatic mutations, and unusual histology. Am J Dermatopathol. 2009;31:664-673. doi:10.1097/DAD.0b013e3181a05dad

49. Vanecek T, Halbhuber Z, Kacerovska D, et al. Large germline deletions of the CYLD gene in patients with Brooke-Spiegler syndrome and multiple familial trichoepithelioma. $\mathrm{Am}$ $J$ Dermatopathol. 2014;36:868-874. doi:10.1097/DAD.00 00000000000068

50. Dobson-Stone C, Hallupp M, Shahheydari H, et al. CYLD is a causative gene for frontotemporal dementia - amyotrophic lateral sclerosis. Brain. 2020;143:783-799. doi:10.1093/brain/ awaa039

51. Cunningham F, Amode MR, Barrell D, et al. Ensembl 2015. Nucleic Acids Res. 2015;43:D662-9. doi:10.1093/nar/gku1010

52. Kupka S, De Miguel D, Draber P, et al. SPATA2-mediated binding of CYLD to HOIP enables CYLD recruitment to signaling complexes. Cell Rep. 2016;16:2271-2280. doi:10.1016/j. celrep.2016.07.086

53. Elliott PR, Leske D, Hrdinka M, et al. SPATA2 links CYLD to LUBAC, activates CYLD, and controls LUBAC signaling. Mol Cell. 2016;63:990-1005. doi:10.1016/j.molcel.2016.08.001

54. Lork M, Verhelst K, Beyaert R. CYLD, A20 and OTULIN deubiquitinases in NF-kappaB signaling and cell death: so similar, yet so different. Cell Death Differ. 2017;24:1172-1183. doi:10.1038/cdd.2017.46

55. Hellerbrand C, Massoumi R. Cylindromatosis-a protective molecule against liver diseases. Med Res Rev. 2016;36:342-359. doi: $10.1002 /$ med.21381

56. Masoumi KC, Shaw-Hallgren G, Massoumi R. Tumor suppressor function of CYLD in nonmelanoma skin cancer. J Skin Cancer. 2011;2011:614097. doi:10.1155/2011/614097

57. Massoumi R. Ubiquitin chain cleavage: CYLD at work. Trends Biochem Sci. 2010;35:392-399. doi:10.1016/j.tibs.2010.02.007

58. Kloepper JE, Ernst N, Krieger K, et al. NF- $\mathrm{kB}$ activity is required for anagen maintenance in human hair follicles in vitro. $J$ Invest Dermatol. 2014;134:2036-2038. doi:10.1038/jid.2014.82

59. Tauriello DV, Haegebarth A, Kuper I, et al. Loss of the tumor suppressor CYLD enhances Wnt/ $\beta$-catenin signaling through K63-linked ubiquitination of Dvl. Mol Cell. 2010;37:607-619. doi:10.1016/j.molcel.2010.01.035

60. Rajan N, Elliott RJ, Smith A, et al. The cylindromatosis gene product, CYLD, interacts with MIB2 to regulate notch signalling. Oncotarget. 2014;5:12126-12140. doi:10.18632/oncotarget.2573

61. Lim JH, Jono H, Komatsu K, et al. CYLD negatively regulates transforming growth factor- $\beta$-signalling via deubiquitinating Akt. Nat Commun. 2012;3:771. doi:10.1038/ncomms 1776

62. Rajan N, Elliott R, Clewes O, et al. Dysregulated TRK signalling is a therapeutic target in CYLD defective tumours. Oncogene. 2011;30:4243-4260. doi:10.1038/onc.2011.133

63. Nagy N, Farkas K, Kemeny L, et al. Phenotype-genotype correlations for clinical variants caused by CYLD mutations. Eur J Med Genet. 2015;58:271-278. doi:10.1016/j.ejmg.2015.02.010

64. Dubois A, Wilson V, Bourn D, et al. CYLD GeneticTesting for Brooke-Spiegler syndrome, familial cylindromatosis and multiple familial trichoepitheliomas. PLoS Curr. 2015;7. doi:10.1371/currents.eogt.45c4e63dd43d62e12228cc5264d6a0db 
65. Hunstig F, Schulz S, Nieten I, et al. A case of Brooke-Spiegler syndrome with a novel mutation in the CYLD gene in a patient with aggressive non-Hodgkin's lymphoma. J Cancer Res Clin Oncol. 2016;142:845-848. doi:10.1007/s00432-015-2079-y

66. Tantcheva-Poor I, Vanecek T, Lurati MC, et al. Report of three novel germline CYLD mutations in unrelated patients with Brooke-Spiegler syndrome, including classic phenotype, multiple familial trichoepitheliomas and malignant transformation. Dermatology. 2016;232:30-37. doi:10.1159/000437303

67. Shiver M, Hughes M, Naylor M, et al. A novel CYLD gene mutation and multiple basal cell carcinomas in a patient with Brooke-Spiegler syndrome. Clin Exp Dermatol. 2016;41:98-100. doi:10.1111/ced.12669

68. Pinho AC, Gouveia MJ, Gameiro AR, et al. Brooke-Spiegler Syndrome - an underrecognized cause of multiple familial scalp tumors: report of a new germline mutation. J Dermatol Case Rep. 2015;9:67-70. doi:10.3315/jdcr.2015.1208

69. Malzone MG, Campanile AC, Losito NS, et al. Brooke-Spiegler syndrome presenting multiple concurrent cutaneous and parotid gland neoplasms: cytologic findings on fine-needle sample and description of a novel mutation of the CYLD gene. Diagn Cytopathol. 2015;43:654-658. doi:10.1002/dc.23275

70. Gao J, Huo L, Sun X, et al. The tumor suppressor CYLD regulates microtubule dynamics and plays a role in cell migration. J Biol Chem. 2008;283:8802-8809. doi:10.1074/jbc.M708470200

71. Sima R, Vanecek T, Kacerovska D, et al. Brooke-Spiegler syndrome: report of 10 patients from 8 families with novel germline mutations: evidence of diverse somatic mutations in the same patient regardless of tumor type. Diagn Mol Pathol. 2010;19:83-91. doi:10.1097/PDM.0b013e3181ba2d96

72. Cakmak Genc G, Dursun A, Nagy N, et al. Brooke-Spiegler syndrome: two patients from a Turkish family with multiple familial trichoepithelioma. Am J Dermatopathol. 2019;41:778-780. doi:10.1097/DAD.0000000000001265

73. Bowen S, Gill M, Lee DA, et al. Mutations in the CYLD gene in Brooke-Spiegler syndrome, familial cylindromatosis, and multiple familial trichoepithelioma: lack of genotype-phenotype correlation. J Invest Dermatol. 2005;124:919-920. doi:10.1111/ j.0022-202X.2005.23688.x

74. Saggar S, Chernoff KA, Lodha S, et al. CYLD mutations in familial skin appendage tumours. $J$ Med Genet. 2008;45:298-302. doi:10.1136/jmg.2007.056127

75. Wu JW, Xiao SX, Huo J, et al. A novel frameshift mutation in the cylindromatosis (CYLD) gene in a Chinese family with multiple familial trichoepithelioma. Arch Dermatol Res. 2014;306:857-860. doi:10.1007/s00403-014-1499-x

76. Grossmann P, Vanecek T, Steiner P, et al. Novel and recurrent germline and somatic mutations in a cohort of 67 patients from 48 families with Brooke-Spiegler syndrome including the phenotypic variant of multiple familial trichoepitheliomas and correlation with the histopathologic findings in 379 biopsy specimens. Am $J$ Dermatopathol. 2013;35:34-44.

77. Hongli J, Lifeng Z, Zhenzhen F, et al. Detection of grass carp reovirus (GCRV) with monoclonal antibodies. Arch Virol. 2014;159:649-655. doi:10.1007/s00705-013-1864-7

78. Reuven B, Margarita I, Dov H, et al. Multiple trichoepitheliomas associated with a novel heterozygous mutation in the CYLD gene as an adjunct to the histopathological diagnosis. $A m$ J Dermatopathol. 2013;35:445-447. doi:10.1097/ DAD.0b013e31827132af

79. Hester CC, Moscato EE, Kazakov DV, et al. A new Cylindromatosis (CYLD) gene mutation in a case of Brooke-Spiegler syndrome masquerading as basal cell carcinoma of the eyelids. Ophthalmic Plast Reconstr Surg. 2013;29:e10-1. doi:10.1097/IOP.0b013e3182565c41
80. Ying ZX, Ma HQ, Liu Y, et al. A novel mutation of CYLD in a Chinese family with multiple familial trichoepithelioma. J Eur Acad Dermatol Venereol. 2012;26:1420-1423. doi:10.1111/ j.1468-3083.2011.04309.x

81. Chen M, Liu H, Fu X, et al. Mutation analysis of the CYLD gene in two Chinese families with multiple familial Trichoepithelioma. Australas J Dermatol. 2011;52:146-147. doi:10.1111/j.14400960.2011.00763.x

82. Kazakov DV, Vanecek T, Zelger B, et al. Multiple (familial) trichoepitheliomas: a clinicopathological and molecular biological study, including CYLD and PTCH gene analysis, of a series of 16 patients. Am J Dermatopathol. 2011;33:251-265. doi:10.1097/ DAD.0b013e3181f7d373

83. Liang YH, Sun CS, Ye XY, et al. Novel substitution and frameshift mutations of CYLD in two Chinese families with multiple familial trichoepithelioma. Br J Dermatol. 2008;158:1156-1158. doi:10.1111/j.1365-2133.2008.08491.x

84. Heinritz W, Grunewald S, Strenge S, et al. A case of Brooke-Spiegler syndrome with a new mutation in the CYLD gene. $\mathrm{Br} J$ Dermatol. 2006;154:992-994. doi:10.1111/j.13652133.2006.07142.x

85. Zheng G, Hu L, Huang W, et al. CYLD mutation causes multiple familial trichoepithelioma in three Chinese families. Hum Mutat. 2004;23:400. doi:10.1002/humu.9231

86. Salhi A, Bornholdt D, Oeffner F, et al. Multiple familial trichoepithelioma caused by mutations in the cylindromatosis tumor suppressor gene. Cancer Res. 2004;64:5113-5117. doi:10.1158/ 0008-5472.CAN-04-0307

87. Poblete Gutierrez P, Eggermann T, Holler D, et al. Phenotype diversity in familial cylindromatosis: a frameshift mutation in the tumor suppressor gene CYLD underlies different tumors of skin appendages. J Invest Dermatol. 2002;119:527-531. doi:10.1046/ j.1523-1747.2002.01839.x

88. Almeida S, Maillard C, Itin P, et al. Five new CYLD mutations in skin appendage tumors and evidence that aspartic acid 681 in CYLD is essential for deubiquitinase activity. J Invest Dermatol. 2008;128:587-593. doi:10.1038/sj.jid.5701045

89. Oranje AP, Halley D, den Hollander JC, et al. Multiple familial trichoepithelioma and familial cylindroma: one cause! J Eur Acad Dermatol Venereol. 2008;22:1395-1396. doi:10.1111/j.14683083.2008.02648.x

90. Young AL, Kellermayer R, Szigeti R, et al. CYLD mutations underlie Brooke-Spiegler, familial cylindromatosis, and multiple familial trichoepithelioma syndromes. Clin Genet. 2006;70:246-249. doi:10.1111/j.1399-0004.2006.00667.x

91. Oiso N, Mizuno N, Fukai K, et al. Mild phenotype of familial cylindromatosis associated with an R758X nonsense mutation in the CYLD tumour suppressor gene. Br J Dermatol. 2004;151:1084-1086. doi:10.1111/j.1365-2133.2004.06231.x

92. Zhang G, Huang Y, Yan K, et al. Diverse phenotype of Brooke-Spiegler syndrome associated with a nonsense mutation in the CYLD tumor suppressor gene. Exp Dermatol. 2006;15:966-970. doi:10.1111/j.1600-0625.2006.00501.x

93. Farkas K, Deak BK, Sanchez LC, et al. The CYLD p.R758X worldwide recurrent nonsense mutation detected in patients with multiple familial trichoepithelioma type 1, Brooke-Spiegler syndrome and familial cylindromatosis represents a mutational hotspot in the gene. BMC Genet. 2016;17:36. doi:10.1186/s12863-016-0346-9

94. Amaro C, Freitas I, Lamarao P, et al. Multiple trichoepitheliomas-a novel mutation in the CYLD gene. J Eur Acad Dermatol Venereol. 2010;24:844-846. doi:10.1111/j.1468-3083.2009.03497.x

95. Espana A, Garcia-Amigot F, Aguado L, et al. A novel missense mutation in the CYLD gene in a Spanish family with multiple familial trichoepithelioma. Arch Dermatol. 2007;143:1209-1210. doi:10.1001/archderm.143.9.1209 
96. Zuo YG, Xu Y, Wang B, et al. A novel mutation of CYLD in a Chinese family with multiple familial trichoepithelioma and no CYLD protein expression in the tumour tissue. $\mathrm{Br}$ $J \quad$ Dermatol. 2007;157:818-821. doi:10.1111/j.13652133.2007.08081.x

97. Ly H, Black MM, Robson A. Case of the Brooke-Spiegler syndrome. Australas J Dermatol. 2004;45:220-222. doi:10.1111/ j.1440-0960.2004.00101.x

98. Wang FX, Yang LJ, Li M, et al. A novel missense mutation of CYLD gene in a Chinese family with multiple familial trichoepithelioma. Arch Dermatol Res. 2010;302:67-70. doi:10.1007/s00403-009-1003-1

99. Nagy N, Farkas K, Kinyo A, et al. A novel missense mutation of the CYLD gene identified in a Hungarian family with Brooke-Spiegler syndrome. Exp Dermatol. 2012;21:967-969. doi:10.1111/exd.12040

100. Huang TM, Chao SC, Lee JY. A novel splicing mutation of the CYLD gene in a Taiwanese family with multiple familial trichoepithelioma. Clin Exp Dermatol. 2009;34:77-80. doi:10.1111/j.1365-2230.2008.02870.x

101. Nasti S, Pastorino L, Bruno W, et al. Five novel germline function-impairing mutations of CYLD in Italian patients with multiple cylindromas. Clin Genet. 2009;76:481-485. doi:10.1111/ j.1399-0004.2009.01259.x

102. Kazakov DV, Schaller J, Vanecek T, et al. Brooke-Spiegler syndrome: report of a case with a novel mutation in the CYLD gene and different types of somatic mutations in benign and malignant tumors. J Cutan Pathol. 2010;37:886-890. doi:10.1111/j.16000560.2010.01511.x

103. Schmidt A, Schmitz R, Giefing M, et al. Rare occurrence of biallelic CYLD gene mutations in classical Hodgkin lymphoma. Genes Chromosomes Cancer. 2010;49:803-809.

104. Kacerovska D, Szep Z, Kollarikova L, et al. A novel germline mutation in the CYLD gene in a Slovak patient with Brooke-Spiegler syndrome. Cesk Patol. 2013;49:89-92.

105. Firth HV, Richards SM, Bevan AP, et al. DECIPHER: database of chromosomal imbalance and phenotype in humans using ensembl resources. Am J Hum Genet. 2009;84:524-533. doi:10.1016/j. ajhg.2009.03.010

106. Nagy N, Rajan N, Farkas K, et al. A mutational hotspot in CYLD causing cylindromas: a comparison of phenotypes arising in different genetic backgrounds. Acta Derm Venereol. 2013;93:743-745. doi:10.2340/00015555-1590
107. $\mathrm{Hu} \mathrm{G}$, Onder M, Gill M, et al. A novel missense mutation in CYLD in a family with Brooke-Spiegler syndrome. J Invest Dermatol. 2003;121:732-734. doi:10.1046/j.1523-1747.20 03.12514.x

108. Pap EM, Farkas K, Szell M, et al. Identification of putative phenotype-modifying genetic factors associated with phenotypic diversity in Brooke-Spiegler syndrome. Exp Dermatol. 2020;29:1017-1020. doi:10.1111/exd.14161

109. Danis J, Kelemen E, Rajan N, et al. TRAF3 and NBR1 both influence the effect of the disease-causing CYLD(Arg936X)

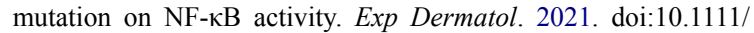
exd.14365

110. Baden HP. Cylindromatosis simulating neurofibromatosis. $N$ Engl J Med. 1962;267:296-297. doi:10.1056/NEJM196208092670608

111. Huang Y, Cai C, Ren L, et al. Marie Unna hereditary hypotrichosis accompanied by multiple familial trichoepithelioma in a Chinese family. J Dermatol. 2019;46:413-417. doi:10.1111/ 1346-8138.14811

112. Dubois A, Rajan N. CYLD cutaneous syndrome. In: Adam MP, Ardinger HH, Pagon RA, editors. GeneReviews $((R))$. Seattle: University of Washington, Seattle Copyright 1993-2020; 1993.

113. Saunders H, Tucker P, Saurine T, et al. Pedigree of multiple benign adnexal tumours of Brooke-Spiegler type. Australas $J$ Dermatol. 2003;44:144-148. doi:10.1046/j.1440-0960.20 03.00663.x

114. Rajan N, Trainer AH, Burn J, et al. Familial cylindromatosis and Brooke-Spiegler syndrome: a review of current therapeutic approaches and the surgical challenges posed by two affected families. Dermatol Surg. 2009;35:845-852. doi:10.1111/j.15244725.2009.01142.x

115. Danilenko M, Stamp E, Stocken DD, et al. Targeting tropomyosin receptor kinase in cutaneous CYLD defective tumors with pegcantratinib: the TRAC randomized clinical trial. JAMA Dermatol. 2018;154:913-921. doi:10.1001/jamadermatol.2018.1610

116. Dubois A, Hodgson K, Rajan N. Understanding inherited cylindromas: clinical implications of gene discovery. Dermatol Clin. 2017;35(1):61-71. doi:10.1016/j.det.2016.08.002

\section{Publish your work in this journal}

The Application of Clinical Genetics is an international, peerreviewed open access journal that welcomes laboratory and clinical findings in the field of human genetics. Specific topics include: Population genetics; Functional genetics; Natural history of genetic disease; Management of genetic disease; Mechanisms of genetic disease;
Counselling and ethical issues; Animal models; Pharmacogenetics; Prenatal diagnosis; Dysmorphology. The manuscript management system is completely online and includes a very quick and fair peerreview system, which is all easy to use. Visit http://www.dovepress. com/testimonials.php to read real quotes from published authors. 